\title{
Acute lower gastrointestinal bleeding: crucial points in inpatient management for optimal urgent colonoscopy
}

We are grateful for the opportunity to reply to the letter "Does the sentence "less is more" apply to bowel preparation?" by Pontone [1]. In accordance with the latest European Society of Gastrointestinal Endoscopy (ESGE) guidelines, which advise against unprepped endoscopy in acute lower gastrointestinal bleeding (LGIB) [2], we totally agree that fasting and the cathartic effect of blood are not sufficient to obtain adequate bowel cleansing.

In addition to this, we would like to underscore the importance of some crucial factors that facilitate optimal quality of urgent colonoscopy in acute LGIB. General and hemodynamic assessment of the patient and adequate resuscitation are the essential steps to define eligibility for endoscopic examination and, in turn, the timing and type of bowel preparation (BP). The timing of endoscopy and the type of BP selected are mutually dependent on each other. Indeed, we have experienced that in high-risk patients with acute hemorrhagic shock and severe cardiovascular comorbidities, a very low-volume and therefore hyperosmolar bowel preparation can achieve optimal cleansing safely and more rapidly [3]. This approach has multiple advantages, including an increased likelihood of identifying the bleeding point, the possibility of performing targeted endoscopic treatment that results in effective hemostasis, and finally, the option to restart antithrombotic therapy sooner when indicated. In addition, we would like to underscore that $1 \mathrm{~L}$ of iso-osmolar bowel preparation is not equivalent to $1 \mathrm{~L}$ of hyperosmolar bowel preparation, and it is unlikely to have the same efficacy compared to $1 \mathrm{~L}$ of the newly available very-low-volume hyperosmolar bowel preparation.

It is useful to know that other groups have experienced similar good results using very-low-volume bowel preparation for colonoscopy in acute LGIB [4].
These observations have also been taken into consideration in the latest ESGE guidelines [2], in which this strategy has been labelled as "encouraging." Therefore, it is highly desirable to continue sharing this expanding knowledge.

\section{Competing interests}

The authors declare that they have no conflict of interest.

\section{The authors}

Paola Soriani ${ }^{1}$, Paolo Biancheri ${ }^{1}$, Cesare Hassan', Mauro Manno ${ }^{1}$

1 Gastroenterology and Digestive Endoscopy Unit, Azienda USL Modena, Carpi, Italy

2 ONRM Hospital, Gastroenterology, Rome, Italy

\section{Corresponding author}

\section{Paola Soriani}

Azienda USL Modena - Gastroenterology and Digestive Endoscopy Unit, Via Guido Molinari 2, Carpi 41012, Italy

Fax: +059 659500

paola.soriani@gmail.com

\section{References}

[1] Pontone S. Does the sentence "less is more" apply to bowel preparation? Endosc Int Open 2021; 09: E1868

[2] Triantafyllou K, Gkolfakis P, Gralnek IM et al. Diagnosis and management of acute lower gastrointestinal bleeding: European Society of Gastrointestinal Endoscopy (ESGE) Guideline. Endoscopy 2021; 53 : 850-868

[3] Soriani P, Biancheri P, Hassan C et al. Updating the recommendations on bowel preparation for acute lower gastro-intestinal bleeding: The time has come! Endosc Int Open 2021; 09: E977-E978
[4] Malik A, Inayat F, Goraya MHN et al. Severe acute colonic diverticular bleeding: the efficacy of rapid bowel preparation with $1 \mathrm{~L}$ polyethylene glycol ascorbate solution and direct endoscopic hemoclipping for successful hemostasis. J Investig Med High Impact Case Rep 2021; 9: doi:10.1177| 2324709621994383

\section{Bibliography}

Endosc Int Open 2021; 09: E1869

DOI 10.1055/a-1594-2318

ISSN 2364-3722

(C) 2021. The Author(s).

This is an open access article published by Thieme under the terms of the Creative Commons Attribution-NonDerivativeNonCommercial License, permitting copying and reproduction so long as the original work is given appropriate credit. Contents may not be used for commercial purposes, or adapted, remixed, transformed or built upon. (https:// creativecommons.org/licenses/by-nc-nd/4.0/)

Georg Thieme Verlag KG, Rüdigerstraße 14, 70469 Stuttgart, Germany

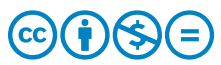

Acute lower gastrointestinal bleeding: crucial points in inpatient management for optimal urgent colonoscopy Paola Soriani, Paolo Biancheri, Cesare Hassan et al.

Endoscopy International Open 2021; 09: E1869.

DOI: 10.1055/a-1594-2318

In the above mentioned article the name of the author Paolo Biancheri was corrected. Correct is: Paolo Biancheri.

This was corrected in the online version on February 3, 2022.

In the above mentioned article the name of the author Paola Soriani was corrected. Correct is: Paola Soriani.

This was corrected in the online version on March 3, 2022. 